Çukurova Üniversitesi Mühendislik Mimarlık Fakültesi Dergisi, 29(2), 69-78 ss., Aralık 2014

Çukurova University Journal of the Faculty of Engineering and Architecture, 29(2), pp. 69-78, December 2014

\title{
Ortaköy Granitoyidi’nin Petrografik ve Jeokimyasal Özellikleri (Yaylak/Aksaray)
}

\author{
Nusret NURLU ${ }^{1}$, Nil YAPICI ${ }^{* 2}$ \\ ${ }^{1}$ Çukurova Üniversitesi, Mühendislik-Mimarlık Fakültesi, Jeoloji Mühendisliği Bölümü, Adana \\ ${ }^{2}$ Çukurova Üniversitesi, Mühendislik-Mimarlık Faültesi, Maden Mühendisliği Bölümü, Adana
}

Geliş tarihi: 17.10.2014 Kabul tarihi: 26.12.2014

\section{Özet}

Aksaray İli, Sarıyahşi İlçesi'ne bağlı Yaylak Köyü mevkiinde yüzeyleyen Ortaköy granitoyidi tonalit, granit, granodiyoritlerden meydana gelmektedir. Üst Kretase (Maestrihtiyen-Kampaniyen) öncesi yaşlı kayaç grubu Kaman metamorfitlerini intrüzif dokanakla keserek bölgeye yerleşmiştir. Kayaçlar, granüler, mikrografik ve poikilitik doku sunmaktadır.

Granitlerde, kuvars, plajiyoklas, ortoklas, biyotit, hornblend, tali mineral olarak zirkon, apatit, epidot, muskovit, granodiyoritilerde, kuvars, plajiyoklas, ortoklas, hornblend, biyotit ve ayrıca zirkon, apatit, sfen klorit türü tali mineraller gözlenmektedir. Tonalit türü kayaçlar ise plajiyoklas, kuvars, ortoklas, biyotit mineralleri ile temsil edilmektedir.

Bölgede yer alan granitoyid, jeokimyasal olarak I-tipi, kalk-alkalen, metalümino-peralümino $(\mathrm{A} / \mathrm{CNK}=0,9-1,1)$ karakter sunmakta olup fraksiyonel kristalleşme sürecine bağlı olarak tek bir magmadan oluştukları izlenmektedir, volkanik yay granitlerinin genel özelliklerini taşıyan bölge granitoyidlerinde yüksek iyon yarıçaplı elementler ( $\mathrm{K}, \mathrm{Rb}, \mathrm{Ba}, \mathrm{Th})$ bakımından okyanus ortası sırtı granitlerine göre zenginleşme, hareketsiz elementlerce ( $\mathrm{Ta}, \mathrm{Nb}, \mathrm{Hf}, \mathrm{Zr}, \mathrm{Sm}, \mathrm{Y}, \mathrm{Yb}$ gibi) okyanus ortası sırtı granitlerine (ORG) benzerlik izlenmektedir. Ta elementinde gözlenen negatif anomali bu kayaçların oluşumunda yitim ve kabuksal kirlenmeye işaret etmektedir.

Anahtar Kelimeler: Ortaköy granotiyodi, Volkanik yay, I-tipi granit, Aksaray/Yaylak

\section{Geochemical and Petrographical Features of Ortaköy Granitoid (Yaylak/Aksaray)}

\begin{abstract}
The Ortaköy granitoid, which crops out near the Yaylak Village of the Sarıyahşi Township of the Aksaray Province, consists of intrusive rocks of tonalite, granite, and granodiorite composition. The Ortaköy granitoid was emplaced within the Late Cretaceous (Maastrichtian-Campanian) Kaman

Yazışmaların yapılacağı yazar: Nil YAPICI, Ç. ̈̈. Mühendislik Mimarlık Fakültesi, Maden Mühendisliği Bölümü, Adana.nyapici@cu.edu.tr
\end{abstract}


metamorphics. Intrusive rocks display granular, micrographic, and poikilitic textures.

Granites consist of quartz, plagioclase, orthoclase, biotite, and hornblende, and lesser amounts of zircon, apatite, epidote, and muscovite, whereas granitoids mainly contain quartz, plagioclase, orthoclase, hornblende, biotite, and subordinate zircon, apatite, sphene, and chlorite. Tonalitic rocks, on the other hand, are characterized by a mineral assemblage of plagioclase, quartz, orthoclase, and biotite.

The intrusive rocks of the region are geochemically of I-type, calc-alkaline, metaluminous to peraluminous $(\mathrm{A} / \mathrm{CNK}=0,9-1,1)$ volcanic arc granites that were formed through fractional crystallization of a single magmatic source. On a mid-ocean ridge granite-normalized (ORGnormalized) trace element diagram, they show enrichments in large ion lithophile elements (LILE) such as $\mathrm{K}, \mathrm{Rb}, \mathrm{Ba}$, and $\mathrm{Th}$, and have similar abundances of immobile elements including $\mathrm{Ta}, \mathrm{Nb}, \mathrm{Hf}, \mathrm{Zr}, \mathrm{Sm}$, $\mathrm{Y}$, and $\mathrm{Yb}$ with ORGs. Negative Ta anomalies observed in these rocks indicate the role of subduction and crustal contamination processes involved in their formation.

Keywords: Ortaköy granitoid, Volcanic arc, I-type granite, Aksaray/Yaylak

\section{GÍRİS}

Aksaray İli, Sarıyahşi İlçesine bağlı Yaylak Köyü mevkiinde bulunan çalışma alanı, Aksaray-K31 paftası içerisinde yer almaktadır (Şekil 1). Bölgedeki kayaçlar, düzenli bir istif sunan metamorfitler, Orta Anadolu metamorfitleri olarak isimlendirilmiştir. Metamorfitler üzerinde yer alan okyanusal kabuğa ait kayalar Orta Anadolu Ofiyolitleri, metamorfitleri ve ofiyolitleri sicak dokanakla kesen farklı kaya türleri içeren felsik ve intrüzif kayalar ise Orta Anadolu Granitoyidleri olarak adlandırılmıştır [1-3]. Tüm bu kayaçlar, Göncüoğlu vd. tarafından Orta Anadolu Kristalen karmaşı ğı olarak adlandırılmıştır [1,2].

Çalışmada, Orta Anadolu Granitoyidleri içerisinde bulunan granitoyid türü kayaçların mineralojik-jeokimyasal ve kökenine yönelik bir yaklaşım getirilmiş̧ir. Bölgede, Koçak (1993), Ortaköy yöresinde migmatit oluşumlarının bölgesel metamorfizma sonucu olduğunu belirtmektedir [4]. Bayhan (1986; 1987; 1993), Ortaköy granitoyidinin petrografisini ve kimyasal, mineralojik özelliklerini incelemiştir [5-7]. Kadığlu ve Güleç (1997), Aksaray/Ağaçören bölgesi intrüziflerin petrolojisini incelemişlerdir [8]. Karakaş ve Kurt (1998) Niğde masifine ait birimlerin jeolojik ve petrografik özelliklerini ortaya koymuşlardır [9].

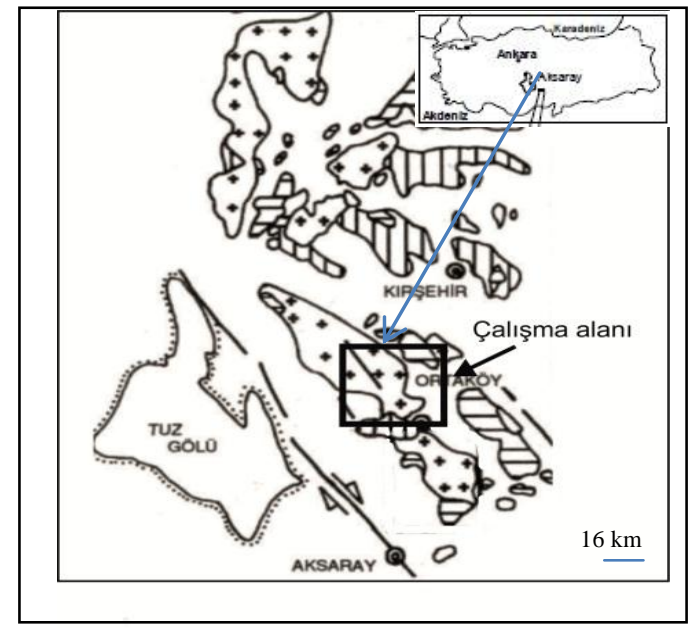

Şekil 1. Çalışma alanı yer bulduru haritası

\section{GENEL JEOLOJI}

$\mathrm{Bu}$ çalışmada, granitoyidler üzerinde yoğunlaşıldığ için ayrıntıll bölgesel jeoloji, önceki çalışmalar [1-9] ve MTA'nın yaptığı jeoloji harita ve açıklamalara göre verilmiştir (Şekil 2) [10].

Kırşehir masifi ile Tuz Gölü arasında yer alan çalışma alanı ve çevresinde Pre-MesozoyikKuvaterner yaş aralığındaki metamorfik magmatik ve çökel kayalar yüzeylenmektedir. Temeli Pre-Mesozoyik yaşlı Kaman Grubuna ait 


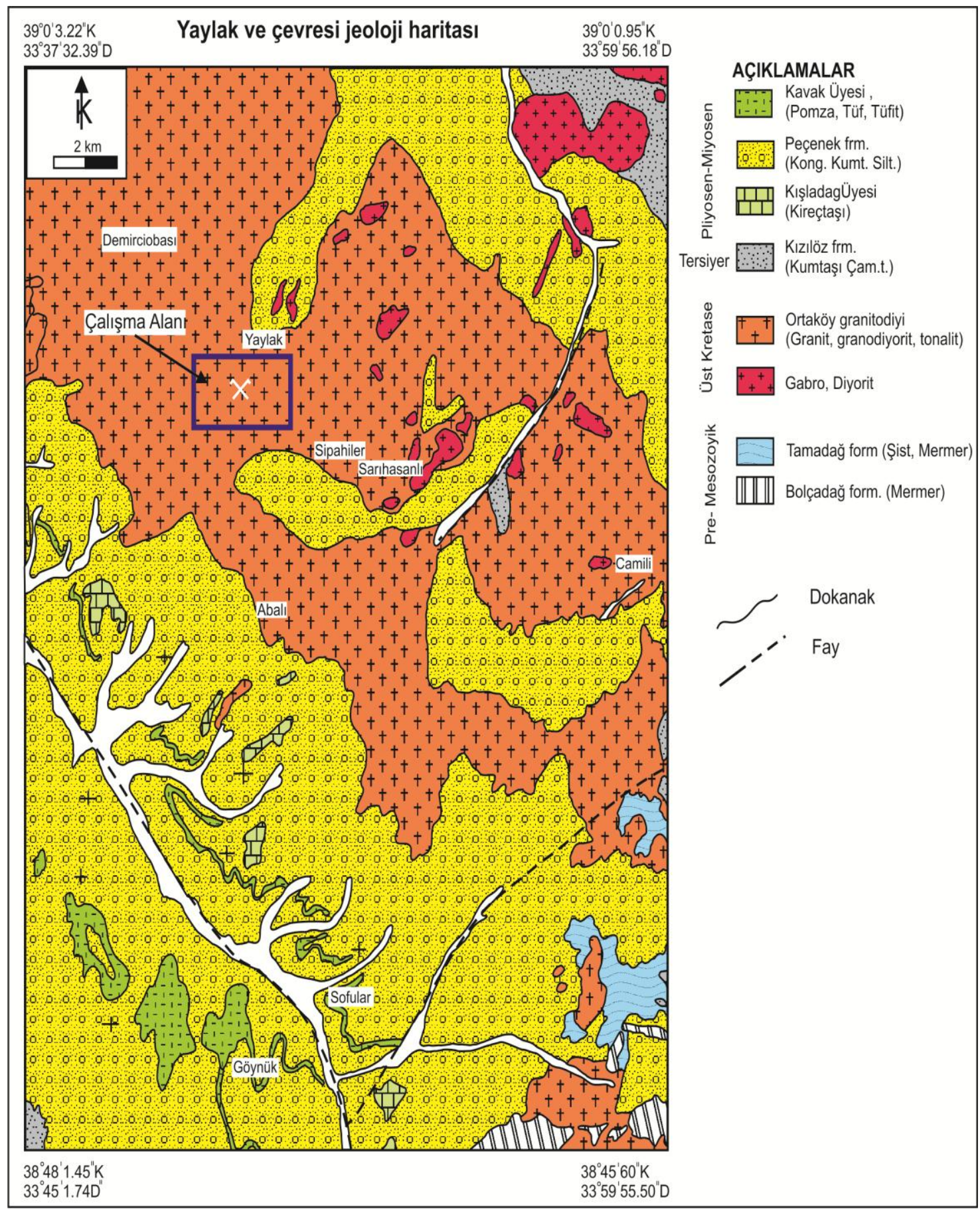

Şekil 2. Çalışma alanı jeoloji haritası (MTA [10]'dan revize edilmiştir). 
Kalkanlıdağ formasyonu, Tamadağ formasyonu ve Bozçaldağ formasyonu oluşturmakta olup bu temeli Kampaniyen öncesi yaşlı Ortaköy granitoyidi kesmektedir. Oligosen yaşlı Mezgit grubuna bağlı Kızılöz formasyonu üstüne uyumsuzlukla gelen Miyosen-Pliyosen yaşlı Peçenek formasyonu, Tesiyer yaşlı kayaç gruplarını oluşturmaktadır.

Üst Kretase-Lütesiyen dönemi denizel ve karasal, Lütesiyen'den genç birimler ise karasal çökeller ile temsil edilmektedir [10] (Şekil 2, Şekil 3).

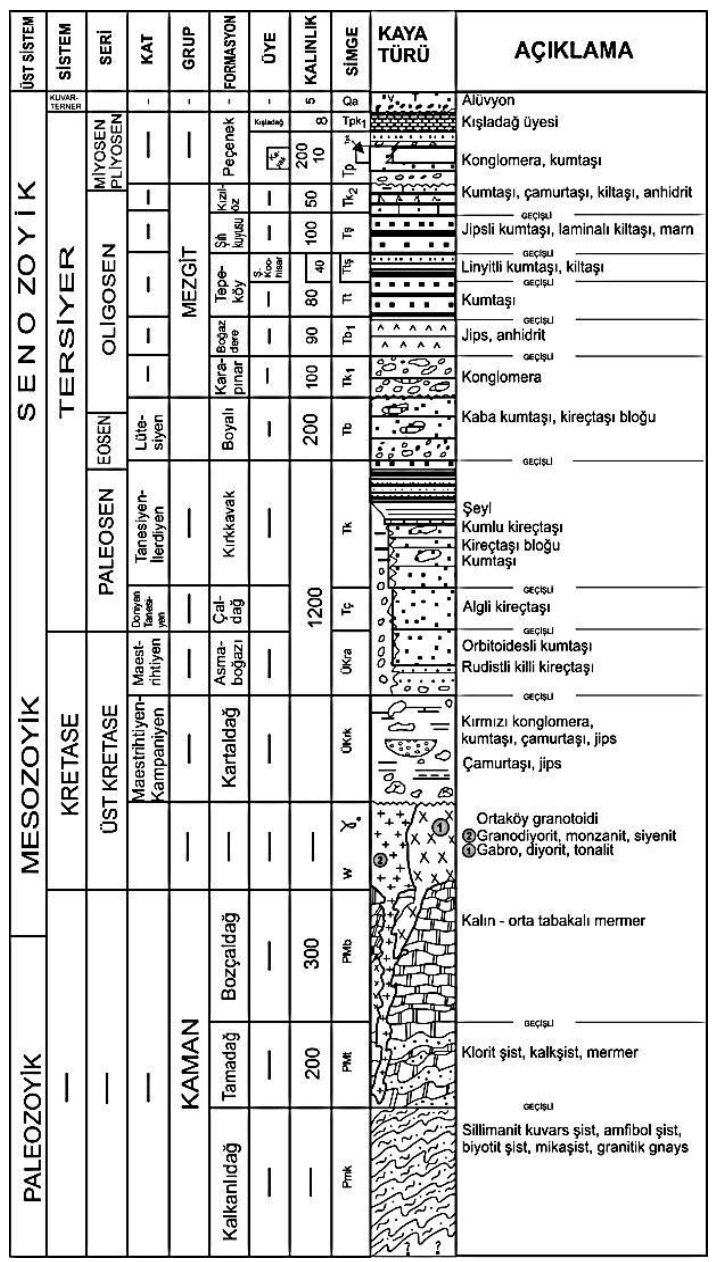

Şekil 3. İnceleme alanının genelleştirilmiş kolon kesiti [10].

\subsection{Ortaköy Granitoyidi}

Ortaköy granitoyidinin Seymen (1981)'deki çalışmasında genel olarak, gabro, diyorit, diyorit porfir, tonalit, granit, granodiyorit, monzonit ve siyenitlerden oluştuğunu ortaya koymuştur. Ancak bu çalışmada temel olarak 3 birim ayırt edilmiş ve bunların granit, graodiyorit ve tonalit oldukları tespit edilmiştir.

Granitoyidin yaşını Seymen (1981) Jura-Kampaniyen yaşlı [11], Batman (1978) Alt Kretase-Kampaniyen öncesi [12], Norman (1972) Türoniyen-Kampaniyen olarak vermekte; Uygun ve di.̆. (1982) [13]. Üst Kretase döneminde Kaman metamorfitlerini sıcak dokanakla kestiğini söylemektedirler [14].

Granitik kayaçlar, granit-alkali granit-granodiyorit ve tonalit türü olmak üzere iki şekilde yüzeylemektedir. Birinci tür kayaçlar gri-boz, pembe renkli, iri kristallidir.

İri ortoklas kristalleri ve ikizleri kayaya porfirik bir doku görünümü kazandırmıştır. $\mathrm{Bu}$ tür kayaçların bulunduğu yerlerde, ayrışma sonucunda granit arenası oluşmuştur. İkinci tür kayaçlar siyahıms1- gri boz renkli ve iri-orta tanelidir [10].

Çalışma alanında yüzeyleyen granitler birinci türde olup granit bileşiminde kalk-alkalen karakterdedir (Şekil 4). Ortaköy Granitoyidine ait çalkılların Kampaniyen-Maestrihtiyen öncesi yaşlı Kartaldağ formasyonu içerisinde bulunması yaşının Kampaniyen Maestrihtiyen öncesi olduğunu göstermektedir [10].

\section{PETROGRAFi}

Ortaköy Granitoyidi, granitden gabroya kadar değişen bir litolojik bileşime sahiptir. Çalışma alanında yüzeyleyen granitoyidler ise daha çok granit, granodiyorit, tonalit türü kayaçlarla temsil edilmektedirler. Granit ve granodiyorit türü kayaçlar alterasyon göstermekte ancak tonalit türü kayaçlar nispeten daha tazedirler (Şekil 5). İnce kesit çalışmalarında granitler granüler, mikrografik ve poiklitik doku sunmaktadırlar (Şekil 5 b). 

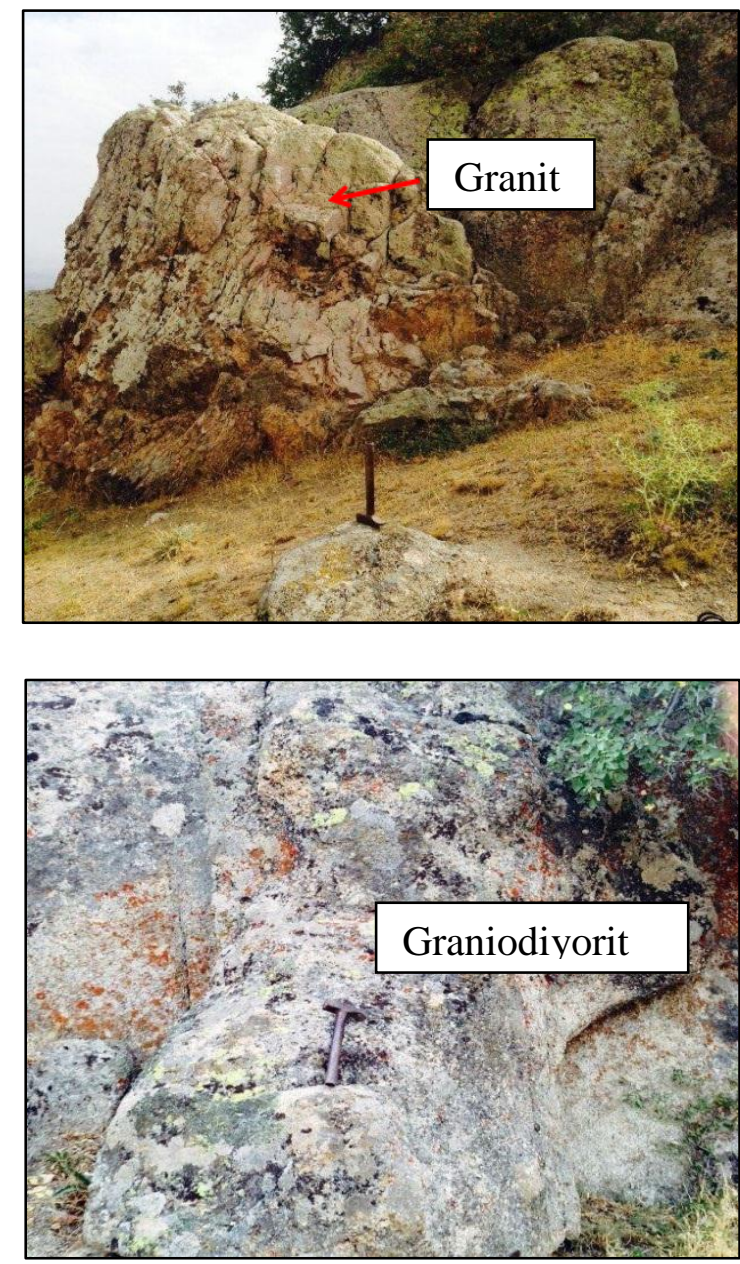

Şekil 4. Kayacın arazi görünümü, gri-boz renkli olup, dış yüzeyleri ayrışmış haldedir.

Majör bileşimleri kuvars \%30-35, plajiyoklas $\% 25-30$, ortoklas \%25-30 biyotit \%5-7, hornblend \%3-4 oranında olmakla beraber tali mineral olarak zirkon, apatit, epidot, muskovit gözlenmektedir (Şekil 5 a,g,h). Granodiyortiler ise hipidyomorfik granüler ve poiklitik doku sunmakta ve kuvars \%35-40, plajiyoklas \%30-40, ortoklas, \%15-20, hornblend \%4-5, biyotit \%2-3 ilksel minerallerinden meydana gelmektedirler (Şekil 5 d), bu kayaçlarda ayrıca zirkon, apatit, sfen klorit türü tali mineraller gözlenmektedir. Tonalit türü kayaçlar ise granüler ve mikrografik doku göstermekte ve majör mineral olarak kuvars
$\% 30-35$, plajiyoklas \%50-55, ortoklas \%5, biyotit $\% 5$ 'ten meydana gelmektedirler (Şekil $5 \mathrm{c}$ ).

\section{JEOKIMYA}

Çalışma alanından derlenen çok sayıda örnek içerisinden seçilen 6 adeti ana-iz ve nadir toprak elementleri (NTE) analizleri için ACME Analytical Laboratuvarına (Kanada) ICP ve ICP-MS yöntemi ile analiz edilmek üzere gönderilmiştir.

Çalışma alanında gözlenen granitik kayaçlara ait örneklerin ana-iz ve nadir toprak element analizleri Çizelge 1'de verilmektedir.

Granitlerde ana oksit ortalama değerleri; $\mathrm{SiO}_{2} \quad \% 73,02, \quad \mathrm{Al}_{2} \mathrm{O}_{3} \quad \% 13,73, \quad \mathrm{Fe}_{2} \mathrm{O}_{3} \quad \% 1,95$ $\mathrm{CaO} \% 2,63, \quad \mathrm{Na}_{2} \mathrm{O}_{3} \% 3,37, \quad \mathrm{MgO} \% 0,33$, $\mathrm{K}_{2} \mathrm{O} \% 3,80$ ve $\mathrm{TiO}_{2} \% 0,17$ granodiyoritlerde; $\mathrm{SiO}_{2} \% 71,67, \mathrm{Al}_{2} \mathrm{O}_{3} \% 14,14, \mathrm{Fe}_{2} \mathrm{O}_{3} \% 2,97 \mathrm{CaO}$ $\% 2,54 \mathrm{Na}_{2} \mathrm{O}_{3} \% 3,18, \mathrm{MgO} \% 0,64, \mathrm{~K}_{2} \mathrm{O} \% 3,70$ ve $\mathrm{TiO}_{2} \% 0,23$ olarak tespit edilmiştir.

Ana element oksitlere dayanılarak çizilen granitik kayaçların adlandırılmasına ilişkin Middlemost (1985) tarafından geliştirilen $\mathrm{Na}_{2} \mathrm{O}+\mathrm{K}_{2} \mathrm{O} / \mathrm{SiO}_{2}$ diyagramında [15]. örnekler granit alanına düşmektedirler (Şekil 6).

Granitik kayaların toplam alkalilerin $\mathrm{SiO}_{2}$ 'e göre değişimi incelendiğinde subalkalen karakterde oldukları ancak AFM diyagramında ise kayaçların tamamının kalk-alkalen karakterde oldukları gözlenmiştir (Şekil 7).

Kayaçların, Shand (1943) tarafından geliştirilen ACNK - ANK diyagramında iki tanesinin metalümino dört adet örneğin ise peralümino $(\mathrm{A} / \mathrm{CNK}=0,9-1,1) \quad$ karakter sunduğu gözlenmektedir (Şekil 8) [17].

Ana element oksit içeriklerinin $\mathrm{SiO}_{2}$ içeriğine karşı değişimlerinin incelendiği Harker (1909) [18] diyagramı analiz edildiğinde $\mathrm{Al}_{2} \mathrm{O}_{3}, \quad \mathrm{FeO}_{\mathrm{t}}, \mathrm{TiO}_{2}$ 

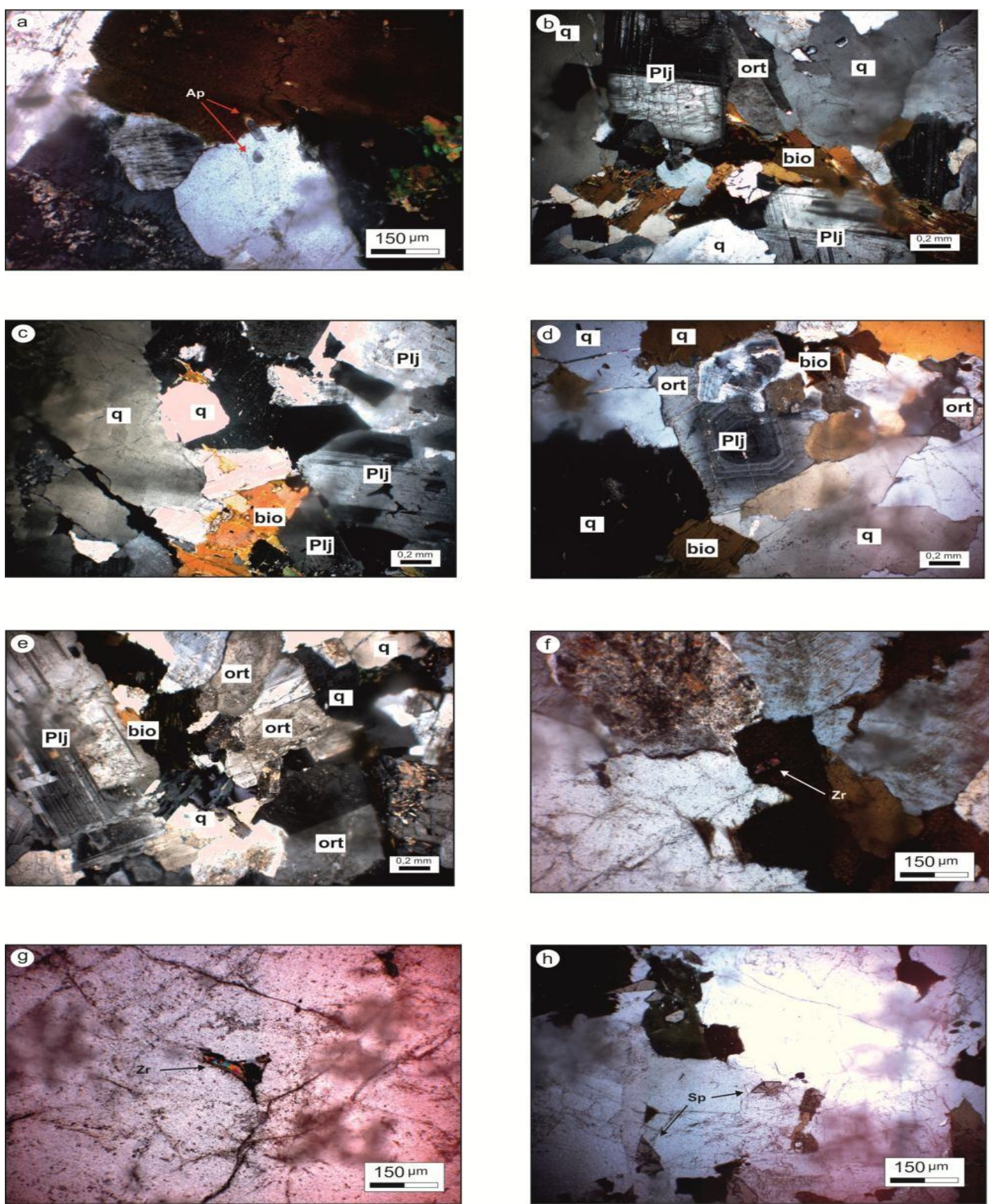

Şekil 5. Ortaköy granitoyidine ait kayaçların mikroskop görüntüleri a) Granitlerde izlenen apatit kristallerinin görüntüsü (Ç.N), b),e) Granitlere ait mikrofotograf(Ç.N), c) Tonalitlerin genel görünümü (Ç.N), d) Granodiyoritlerin genel görünümü, (Ç.N), g), f) Granitlerde gözlenen zirkon kristalleri(Ç.N), h) Granodiyoritlerde gözlenen sfen kristalleri (Ç.N), (q: kuvars, ort: ortoklas, plj: plajiyoklas, bio: biyotit, zr: zirkon, sp: sfen, ap: apatit Ç.N:Çift Nikol) 
Çizelge 1. Örneklere ait kimyasal analiz sonuçları (GD:Granodiyorit, G:Granit)

\begin{tabular}{|c|c|c|c|c|c|c|}
\hline Ana oksitler (\%) & GD1 & GD2 & GD3 & GD4 & G1 & G2 \\
\hline $\mathrm{SiO}_{2}$ & 71,93 & 72,10 & 71,36 & 71,30 & 73,02 & 73,02 \\
\hline $\mathrm{Al}_{2} \mathrm{O}_{3}$ & 14,04 & 13,87 & 14,31 & 14,34 & 13,72 & 13,74 \\
\hline $\mathrm{Fe}_{2} \mathrm{O}_{3}$ & 2,90 & 2,87 & 3,03 & 3,07 & 1,97 & 1,94 \\
\hline $\mathrm{MgO}$ & 0,65 & 0,64 & 0,63 & 0,63 & 0,33 & 0,33 \\
\hline $\mathrm{CaO}$ & 2,56 & 2,54 & 2,53 & 2,52 & 2,62 & 2,63 \\
\hline $\mathrm{Na}_{2} \mathrm{O}$ & 3,16 & 3,18 & 3,19 & 3,18 & 3,35 & 3,38 \\
\hline $\mathrm{K}_{2} \mathrm{O}$ & 3,65 & 3,66 & 3,74 & 3,76 & 3,78 & 3,81 \\
\hline $\mathrm{TiO}_{2}$ & 0,22 & 0,22 & 0,23 & 0,23 & 0,17 & 0,17 \\
\hline $\mathrm{P}_{2} \mathrm{O}_{5}$ & 0,06 & 0,05 & 0,04 & 0,04 & 0,09 & 0,08 \\
\hline $\mathrm{MnO}$ & 0,09 & 0,09 & 0,09 & 0,09 & 0,04 & 0,04 \\
\hline $\mathrm{Cr}_{2} \mathrm{O}_{3}$ & $<0,002$ & 0,003 & $<0,002$ & $<0,002$ & $<0,002$ & $<0,002$ \\
\hline LOI & 0,6 & 0,6 & 0,7 & 0,7 & 0,8 & 0,7 \\
\hline Top. $\%$ & 99,87 & 99,87 & 99,86 & 99,87 & 99,84 & 99,83 \\
\hline \multicolumn{7}{|l|}{ İz elementler (ppm) } \\
\hline $\mathrm{Ni}$ & $<20$ & $<20$ & $<20$ & $<20$ & $<20$ & $<20$ \\
\hline Sc & 3 & 3 & 3 & 4 & 5 & 5 \\
\hline $\mathbf{B a}$ & 648 & 649 & 695 & 681 & 782 & 769 \\
\hline $\mathrm{Be}$ & $<1$ & 2 & 1 & 2 & 3 & 3 \\
\hline Co & 3,2 & 3,4 & 3,4 & 3,5 & 1,8 & 2,0 \\
\hline Cs & 3,3 & 3,4 & 3,7 & 3,5 & 1,5 & 1,7 \\
\hline Ga & 11,3 & 10,6 & 11,7 & 11,9 & 12,2 & 12,9 \\
\hline Hf & 3,3 & 3,4 & 3,7 & 3,7 & 9,5 & 10 \\
\hline $\mathrm{Nb}$ & 9,9 & 9,5 & 8,8 & 9,0 & 4,3 & 4,5 \\
\hline $\mathrm{Rb}$ & 132,7 & 134,9 & 137,6 & 136,4 & 98,5 & 99,1 \\
\hline Sn & 1 & 1 & 2 & 2 & 1 & 2 \\
\hline $\mathrm{Sr}$ & 199,7 & 197,1 & 196,2 & 196,6 & 127,5 & 128,5 \\
\hline $\mathrm{Ta}$ & 1,0 & 1,1 & 0,9 & 1,0 & 0,4 & 0,4 \\
\hline Th & 16,0 & 15,9 & 16,4 & 18,8 & 24,1 & 22,6 \\
\hline $\mathrm{U}$ & 6,0 & 5,4 & 4,7 & 5,1 & 8,3 & 4,9 \\
\hline V & 21 & 22 & 24 & 25 & 15 & 15 \\
\hline $\mathbf{W}$ & $<0,5$ & $<0,5$ & $<0,5$ & $<0,5$ & $<0,5$ & $<0,5$ \\
\hline $\mathrm{Zr}$ & 115,6 & 116 & 125,7 & 127,4 & 314,1 & 331,9 \\
\hline$Y$ & 15,9 & 16,5 & 15,0 & 15,7 & 25,5 & 24,5 \\
\hline Mo & 0,4 & 0,4 & 0,5 & 0,3 & 0,4 & 0,4 \\
\hline $\mathrm{Cu}$ & 5,1 & 5,1 & 8,7 & 8,4 & 10,9 & 11,1 \\
\hline $\mathrm{Pb}$ & 4,3 & 4,6 & 5,6 & 5,3 & 3,7 & 3,8 \\
\hline $\mathrm{Zn}$ & 44 & 47 & 44 & 45 & 28 & 28 \\
\hline As & 1,1 & 0,9 & 1,7 & 1,7 & $<0,5$ & $<0,5$ \\
\hline $\mathrm{Cd}$ & $<0,1$ & $<0,1$ & $<0,1$ & $<0,1$ & $<0,1$ & $<0,1$ \\
\hline $\mathrm{Sb}$ & 0,1 & $<0,1$ & 0,2 & 0,2 & 0,1 & $<0,1$ \\
\hline $\mathrm{Bi}$ & 0,1 & $<0,1$ & 0,2 & 0,2 & 0,1 & $<0,1$ \\
\hline $\mathrm{Ag}$ & $<0,1$ & $<0,1$ & $<0,1$ & $<0,1$ & $<0,1$ & $<0,1$ \\
\hline $\mathrm{Au}$ & 1,6 & 1,0 & 0,7 & 0,8 & $<0,5$ & $<0,5$ \\
\hline $\mathrm{Hg}$ & $<0,01$ & $<0,01$ & $<0,01$ & $<0,01$ & $<0,01$ & $<0,01$ \\
\hline T1 & 0,3 & 0,3 & 0,3 & 0,2 & 0,2 & 0,2 \\
\hline $\mathrm{Se}$ & $<0,5$ & $<0,5$ & $<0,5$ & $<0,5$ & $<0,5$ & $<0,5$ \\
\hline \multicolumn{7}{|c|}{ Nadir elementler (REE, ppm) } \\
\hline La & 31 & 31,4 & 29,8 & 34,6 & 54,8 & 49,7 \\
\hline $\mathrm{Ce}$ & 54,6 & 56,8 & 55,8 & 62,3 & 109,8 & 101,1 \\
\hline Pr & 5,55 & 5,69 & 5,51 & 6,33 & 11,98 & 11,27 \\
\hline $\mathrm{Nd}$ & 19,4 & 19,3 & 17,5 & 21,6 & 43,0 & 41,2 \\
\hline $\mathrm{Sm}$ & 3,02 & 3,16 & 2,98 & 3,34 & 7,73 & 7,11 \\
\hline Eu & 0,60 & 0,67 & 0,63 & 0,65 & 0,94 & 0,97 \\
\hline Gd & 2,92 & 2,76 & 2,65 & 2,88 & 5,73 & 5,89 \\
\hline $\mathrm{Tb}$ & 0,44 & 0,43 & 0,42 & 0,44 & 0,84 & 0,81 \\
\hline Dy & 2,60 & 2,40 & 2,38 & 2,45 & 4,28 & 4,52 \\
\hline Ho & 0,56 & 0,54 & 0,50 & 0,51 & 0,83 & 0,86 \\
\hline Er & 1,61 & 1,53 & 1,60 & 1,60 & 2,44 & 2,56 \\
\hline $\mathrm{Tm}$ & 0,26 & 0,27 & 0,24 & 0,26 & 0,39 & 0,41 \\
\hline $\mathrm{Yb}$ & 1,84 & 1,89 & 1,63 & 1,85 & 2,58 & 2,74 \\
\hline Lu & 0,31 & 0,31 & 0,28 & 0,29 & 0,41 & 0,45 \\
\hline
\end{tabular}




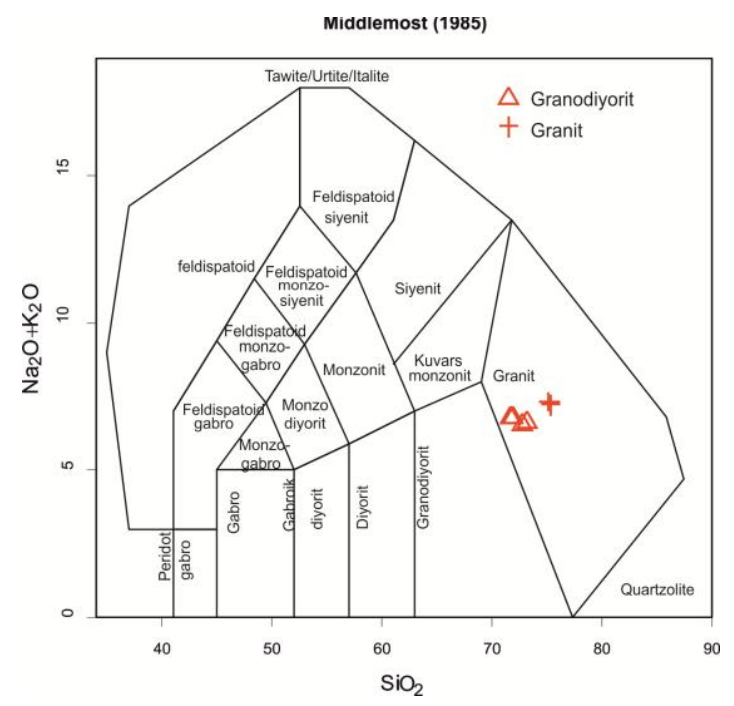

Şekil 6. Çalışma alanında gözlenen granitik kayalara ait adlandırma diyagramı [15].

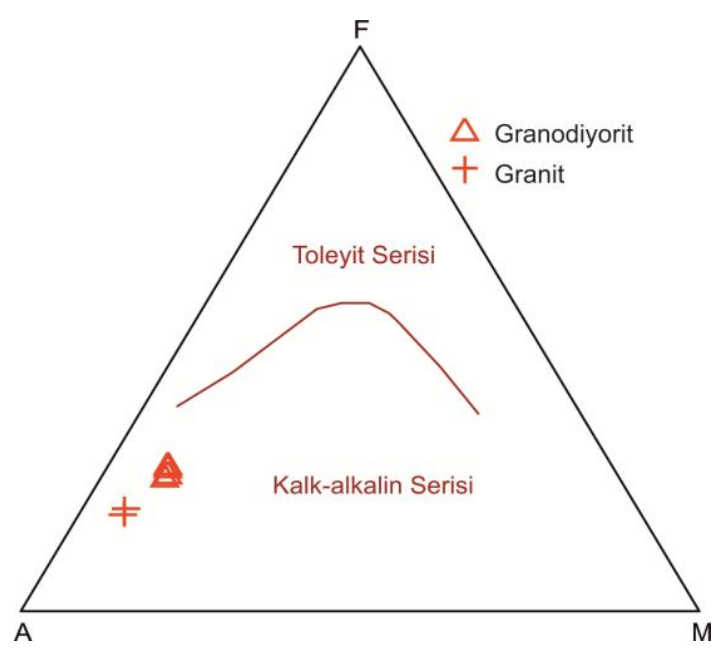

Şekil 7. Granitik kayaçların AFM diyagramındaki konumlarını gösterir diyagram [16].

element oksitlerinin $\mathrm{SiO}_{2}$ 'e karşı negatif anomali gösterdikleri, $\mathrm{MgO}, \mathrm{Na}_{2} \mathrm{O}, \mathrm{K}_{2} \mathrm{O}, \mathrm{P}_{2} \mathrm{O}_{5}$, ve $\mathrm{CaO}$ element oksitlerinin ise $\mathrm{SiO}_{2}$ 'e karşı pozitif anomali gösterdikleri gözlenmekte ve bu özelliklere dayanılarak Ortaköy grantoyidine ait kayaçların, fraksiyonel kristalleşme sürecine bağlı olarak tek bir magma kaynağından oluştukları ortaya konabilmektedir (Şekil 9).

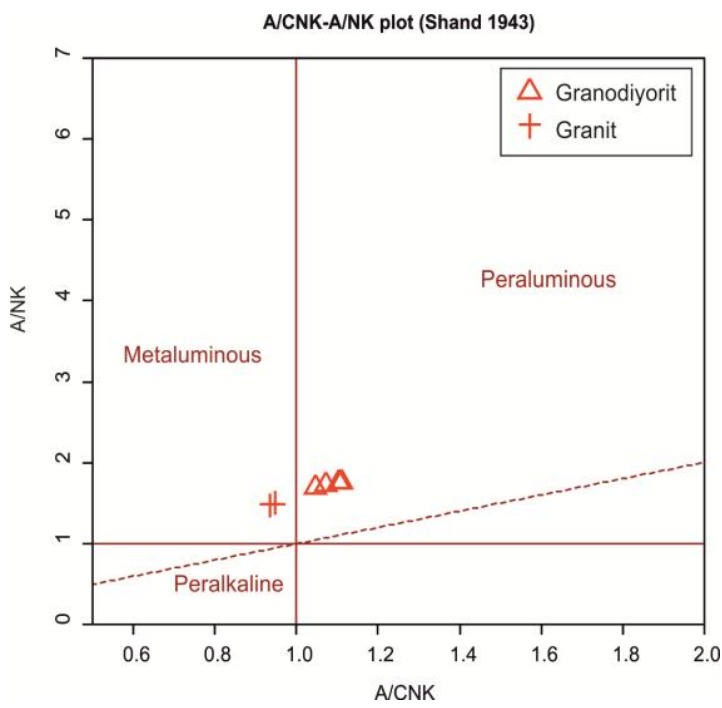

Şekil 8. Granitoyidlerin ACNK diyagramı [17].

$\mathrm{Rb}-\mathrm{Yb}-\mathrm{Y}-\mathrm{Ta}+\mathrm{Yb}-\mathrm{Yb}$ elementleri kullanilarak hazırlanan Pearce ve diğ. (1984) [19-20] diyagramları incelendiğinde $\mathrm{Rb}-\mathrm{Y}+\mathrm{Nb}$, $\mathrm{Rb}-\mathrm{Ta}+\mathrm{Yb}, \mathrm{Ta}-\mathrm{Yb}$ diyagramlarının her üçünde de örneklerin volkanik yay graniti alanına düştükleri, Nb-Y diyagramında ise Volkanik yay graniti ve Çarpışmayla eşyaşlı (Syn-collisional) granitoyidler alanına düştükleri gözlenmekte olup bu durumda Ortaköy granitoyidinin volkanik yay granitoyidi olduğu söylenebilir (Şekil 10).

Çalışma alanında gözlenen granitoyidlerden derlenen örneklerin okyanus ortası sırtı granitlerine (ORG) göre normalize edilmiş örümcek diyagramında kayaçlarda genel olarak yüksek iyon yarıçaplı elementler $(\mathrm{K}, \mathrm{Rb}, \mathrm{Ba}, \mathrm{Th})$ bakımından okyanus ortası sırtı granitlerine göre zenginleşme, hareketsiz elementlerce $(\mathrm{Ta}, \mathrm{Nb}, \mathrm{Hf}$, $\mathrm{Zr}, \mathrm{Sm}, \mathrm{Y}, \mathrm{Yb}$ gibi) okyanus ortas1 sirt1 granitlerine (ORG) benzerlik izlenmektedir (Şekil 11). $\mathrm{Nb}$ ve Ta elementlerinde gözlenen negatif anomali bu kayaçların oluşumunda yitim ve kabuksal kirlenmeye işaret etmektedir (Pearce, 1984).

\section{SONUÇLAR}

$\mathrm{Bu}$ çalışmada, Aksaray İli, Sarıyahşi ilçesine bağlı Yaylak Köyü mevkiinde bulunan Ortaköy 

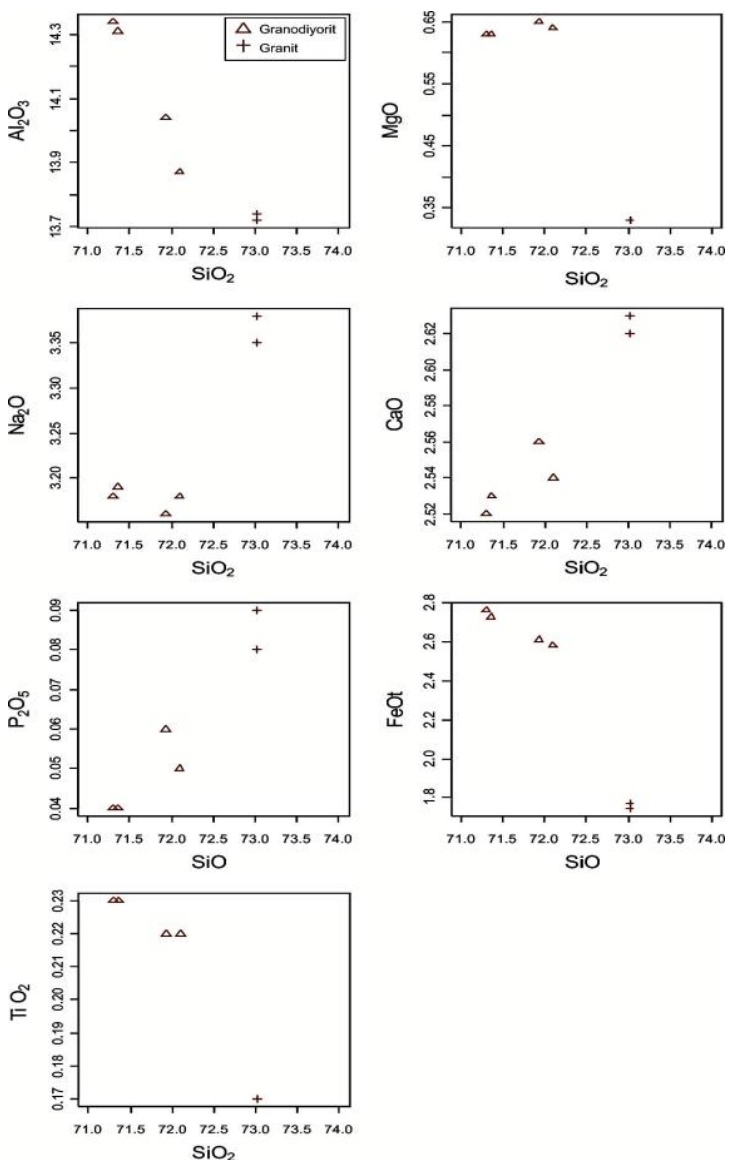

Şekil 9. Ortaköy granitoyidine ait kayaçların ana element Harker (1909) diyagramı

granitoyidi içerisindeki felsik grup kayaçların petrografisi, mineralojisi ve jeokimyası incelenmiştir. Bölgeden alınan granitoyid örnekleri daha çok granit, granodiyorit, tonalit türü kayaçlarla temsil edilmektedirler. Arazi gözlemlerinde granit ve granodiyorit türü kayaçlar alterasyon göstermekte, tonalit türü kayalar daha taze örneklerle temsil edilmektedir. İnce kesit çalışmalarında ise granitler, granüler, mikrografik ve poiklitik doku sunmakta olup, mineral içerikleri çoktan aza doğru kuvars, plajiyoklas, ortoklas, biyotit, hornblend, tali mineral olarak zirkon, apatit, epidot, muskovit, granodiyortilerde, kuvars, plajiyoklas, ortoklas, hornblend, biyotit ve ayrica zirkon, apatit, sfen klorit türü tali mineraller gözlenmektedir.
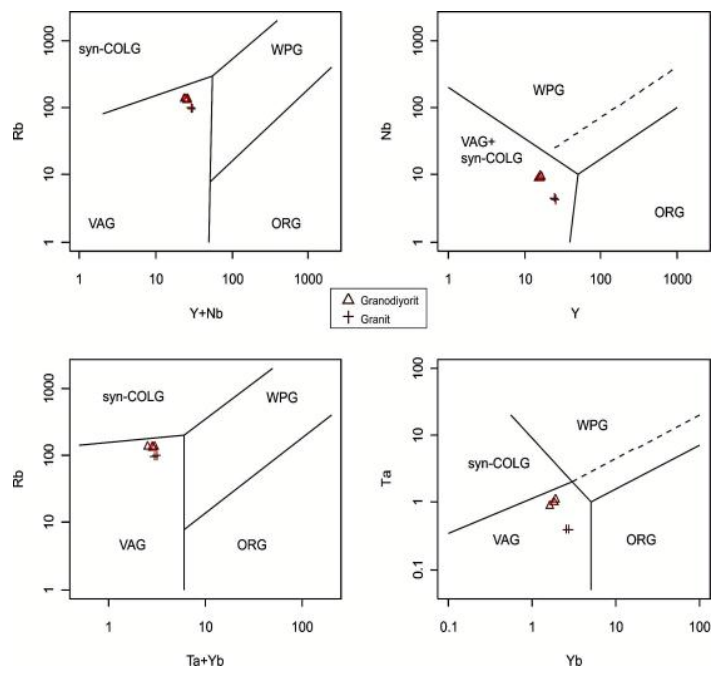

Şekil 10. Çalışma alanındaki granitoyidlerin tektonomagmatik diskriminasyon diyagramlar1 $(19,20)$

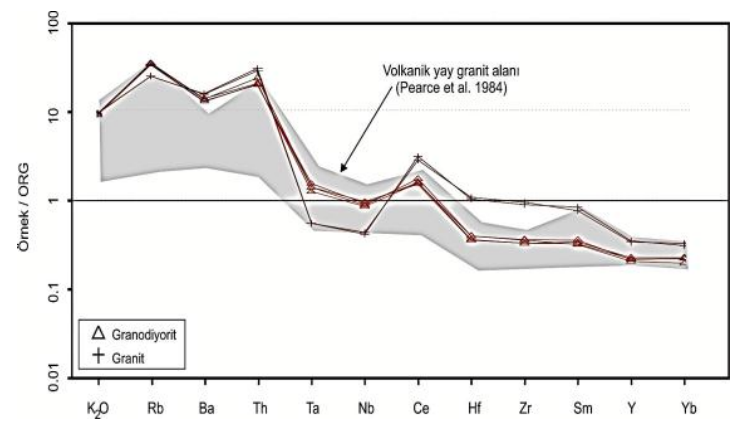

Şekil 11. Ortaköy granitoyidine ait kayaçların okyanus ortası sırtı granitlerine (ORG) göre normalize edilmiş örümcek diyagramı.

Tonalit türü kayaçlar ise plajiyoklas, kuvars, ortoklas, biyotit mineralleri ile temsil edilmektedir.

Kimyasal içeriklerindeki ana element oksitlere dayanılarak çizilen diyagramlara göre kayaçların granit olduğu, AFM diyagramına göre kalk-alkalen karakterde olduğu tespit edilmiş, granitlerin fraksiyonel kristalleşme sürecine bağlı olarak tek bir magmadan oluştukları ortaya konulmuştur. $\mathrm{Rb}$ $\mathrm{Yb}-\mathrm{Y}-\mathrm{Ta}+\mathrm{Yb}-\mathrm{Yb}$ elementleri kullanılarak hazırlanan diyagramda tüm örneklerin volkanik 
yay graniti oldukları söylenebilmektedir. Çalışma alanında gözlenen granitoyidler okyanus ortası sırtı granitlerine (ORG) göre normalize edilmiş örümcek diyagramında genel olarak yüksek iyon yarıçaplı elementler ( $\mathrm{K}, \mathrm{Rb}, \mathrm{Ba}, \mathrm{Th})$ bakımından okyanus ortası sırtı granitlerine göre zenginleşme, hareketsiz elementlerce (Ta, Nb, Hf, Zr, Sm, Y, Yb) ortası sirt1 granitlerine (ORG) benzerlik izlenmektedir ve Ta elementlerinde gözlenen negatif anomali bu kayaçların oluşumunda yitim ve kabuksal kirlenmeye işaret etmektedir.

\section{KAYNAKLAR}

1. Göncüoğlu, M. C., Toprak, V., Kuşcu, İ., Erler, A., Olgun, E., 1991. Orta Anadolu Masifinin Batı Bölümünün Jeolojisi, Bölüm 1-Güney Kesim: TPAO Rapor No. 2909, s. 140, yayınlanmamış.

2. Göncüoğlu, M. C., Toprak, V., Kuşçu, İ., Erler, A., Olgun, E., Rojay, B., 1992. Orta Anadolu Masifinin Batı Bölümünün Jeolojisi, Bölüm 2: Orta Kesim, T.P.A.O., Rap. No: 3155, 76s.

3. Güllü, B., Yildı, M., 2012. Mamasun (Aksaray) Gabroyidlerinin Petrojenetik Karakteristiği, KSU Mühendislik Bilimleri Dergisi, 15(1), Kahramanmaraş.

4. Koçak, K., 1993. The Petrology and Geochemistry of the Ortaköy Area, Central Turkey, PhD thesis, Glasgow Uni., Scotland, 280 (unpublished).

5. Bayhan, H., 1986. İç Anadolu Granitoyid Kuşağındaki Çelebi Sokulumunun Jeokimyas ve Kökensel Yorumu. Jeoloji Müh. Derg. 29, 27-36.

6. Bayhan, H., 1987. Cefalıkdağ ve Baranadă̆ Plütonlarının (Kaman) Petrografik ve Kimyasal Mineralojik Özellikleri. Jeo. Müh. Derg. 30, 11-16.

7. Bayhan, H., 1993. Ortaköy Granitoyidinin (Tuzgölü doğusu) Petrografik ve KimyasalMineralojik Özellikleri. Doğa-Türk Yerbilim. Dergisi, 2, 147- 160.

8. Kadıŏlu, Y.K., Güleç, N. 1997. Ağaçören İntrüzif Takımının Petrolojisi (Aksaray), Çukurova Üniversitesinde Jeoloji Mühendisliği Eğitiminin 20.Y1lı Sempozyumu, 30 Nisan-3 May1s 1997.
9. Karakaș, M., Kurt, H., 1998. Himmetli-Elmal1Kızılören (Niğde) Dolayının Jeolojisi, Mineralojisi ve Jeokimyas1, Frrat Üniversitesi 20. Y1l Sempozyumu Bildirileri, 369-379.

10. MTA 1989. Türkiye Jeoloji Haritalar Serisi, Aksaray H17, K31 paftas1, Ankara (2011 revize).

11. Seymen, İ., 1981. Kaman (Kırşehir) Dolayında Kırşehir Masifinin Stratigrafisi ve Metamorfizmas1, TJK Bült., 24/2, d.101-108.

12. Batman, B., 1978. Haymana Kuzeyinin Jeolojik Evrimi ve Yöredeki, Melanjın İncelenmesi, Yerbilimleri dergisi c.4, s.95-124.

13. Norman, T., 1972. Ankara Bölgesinde Üst Kretase-Alt Tersiyer İstifinin Stratigrafisi, TJK, XV., s.172-180,

14. Uygun, A., 1981. Tuz Gölü Havzasının Jeolojisi, Evaporit Oluşumları ve Hidrokarbon Olanakları, TJK, İç Anadolunun Jeolojisi Sempozyumu, s.66-71.

15. Middlemost, E.A.K., 1985. Magmas and Magmatic Rocks: An Introduction to Igneous Petrology. London, New York: Longman.

16. Irvine T. N., Baragar, W. R. A., 1971. A Guide to the Chemical Classification of the Common Volcanic Rocks, Can", J. Earth Sci., 8:523-48.

17. Shand, S., J. 1943. Eruptive Rocks. Their Genesis, Composition, Classification, and Their Relation to Ore-Deposits with a Chapter on Meteorite, New York: John Wiley \& Sons.

18. Harker, A., 1909. The Natural History of Igneous Rocks, London, Metheuen, 384s.

19. Pearce, J. A., Lippard, S. J., Roberts, S., 1984a. Characteristics and Tectonic Significance of Suprasubduction Zone Ophiolites, In: Kokelaar, B. P and Howells, M. F (eds.), Marginal Basin Geology, Geological Society of London, Special Publication, 16: 77-94.

20. Pearce, J. A., Harris, N. B. W., Tindle, A. G., 1984b. Trace Element Discrimination Diagram for the Tectonic Interpretation of Granitic Rocks, Journ.of Petrol, 25:956-983. 